\title{
A Review on Petroleum Refining and Petrochemical Processes with Special Emphasis on Catalysts and Flue Gas Treatment Technology
}

\author{
Sunil Jayant Kulkarni \\ Datta Meghe College of Engineering \\ Airoli, Navi Mumbai, Maharashtra, India \\ suniljayantkulkarni@gmail.com
}

\begin{abstract}
Petrochemical and Petroleum refining sector has become the backbone of the economical development. The costs of all the consumer goods are closely governed by cost of petroleum products. Diesel and petrol are two most widely used liquid fuels in the world. The cost of the fuel depends on the raw material. The optimization of the reaction carried out in these industries can save some cost and add to economy. The catalyst cracking is important part of these processes. Effective and efficient use of catalyst in desulphurization is key to economical operation of the process. In the developing countries the emission from these industries is important operational problem. The current review summarizes research and studies on these two aspects (catalyst and flue gas treatment) with respect to materials used, methodology and effectiveness.
\end{abstract}

Keywords: Simulation, cracking, oxides, sorbents, feed stocks, treatment.

\section{INTRODUCTION}

The current era of rapid industrialization calls for economical and environmental friendly technology in each sector. The chemical and petrochemical engineering and technology involves the development and application of cost effective and environmental friendly technologies. In various fields of chemical engineering, the process intensification to save energy, time and space is being carried out with moderate to high success rate. The use of reactive chromatography, reactive adsorption, hydrotropy and pinch technology has become frequent in the chemical and petrochemical industries $[1,2,3,4]$. Use of effective catalyst is also key to many chemical processes[5,6,7,8]. The treatment of flue gases from petroleum industries also calls for cost effective and ecofriendly method[9,10,11,12]. The current review deals with these two major aspects of petrochemical and refining industries.

\section{Catalysts in Petrochemical and Petrolium Refining Processes}

Saidi et.al. carried out modeling of and simulation of continuous catalytic regeneration process(CCR)[13].the CCR process is very important in petrochemical and petroleum refining for octane improvement and production of aromatic feedstock. They used a process model based on a 12 lumped kinetics reaction network. They carried out reaction modeling along with mass and heat balancing. In their lumping technique, they lumped the parameters in to $\mathrm{C}_{1}, \mathrm{C}_{2}, \mathrm{C}_{3}, \mathrm{C}_{4}, \mathrm{C}_{5}, \mathrm{p}$ (paraffin), $\mathrm{n}$ (naphthalene), a (aromatic) and $\mathrm{H}_{2}$. They observed that the obtained simulation operating result are in appropriate agreement with the industrial plant data. For catalytic naphtha reforming, they developed a model with 25 lumps. According to their results, perfect agreement of compositions at the exit of the reactor is obtained between simulated values and reported values. Kovin et.al. studied catalytic cracking with Russian perspective[14]. According to their studies, there was a need to modernize Russian refineries based on catalytic cracking with maximum application of domestic technologies. This will make it possible to increase high-quality fuels production in shortest time with relatively low capital expenditures. Marcilly studied the importance of zeolites in the modern refining and petrochemical evolution [15]. He presented the evolution of the refining and petrochemical industries during the last two or three decades and the principal trends of their evolution in the medium and long run. He also presented the market of zeolites for various industrial applications (detergency, sorption/drying and catalysis) and their applications in refining and petrochemicals. According to him, zeolitic catalysts contribute substantially to refining and petrochemical industry. 
He concluded on a note that development of any new process always comes up against an unavoidable need to be profitable and competitive, which is often a difficult obstacle to overcome.

A study was carried out on nanosized molecular sieves as petroleum refining and petrochemical catalysts by Xuhong et.al.[16]. Marcilly surveyed the remarkable development that has taken place in catalysis in the refining and petrochemical industries since the middle of the 20th century, and more especially since the 1970s [17]. According to them, oil will still remain the principal source of liquid motor fuels for a long time. It is necessary to pursue the technical changes that have been under way for the last 30 years. The progress in the field of catalyst selectivity is most important aspect of innovations and advancements. Mohaddecy et.al. carried out an investigation on optimization of catalyst distribution in the catalytic naphtha reformer[18]. This study was carried out with respect to Tehran refinery. They used hysys-refinery simulator. They studied effect of catalyst distribution on the octane number of produced gasoline with all other parameters constant. The results of their simulation indicated that the proposed distribution can increase the octane number and octane barrel values in the period of four months of plant data studied. Curry carried out studies on platinum catalyst for petroleum refining [19]. He emphasized that catalytic refining is gaining importance as it enables improvement in octane rating. Emam studied clays as catalyst for in petroleum refining industry [20]. He noted that clays are used in petroleum industry for number of processes like catalytic cracking, hydrocracking, reforming, isomerization, hydrogenation, alkylation etc. According to him, kaolin and montmorillonite are most important clays used. He observed that pillared clays are very interesting and promising catalysts in a broad range of application. Also according to these studies, palygorskite and sepiolite clays are gaining increasing importance.

\section{Flue Gas Treatment in Petrochemical and Petrolium Refining Process}

Chapel and Mariz carried out studies on commercial trends in recovery of $\mathrm{CO}_{2}$ from flue gases [21]. They reviewed the latest operating and capital cost data for the Fluor Daniel Econamine FGSM process. These studies indicated that reduction in steam consumption can be important area in improving the economy. Improved oxygen inhibitors and economizing the materials used in cooling and absorption can reduce the cost further. They concluded that economy of scale have the potential of delivering $\mathrm{CO}_{2}$ at a price approximately half that of the reference 1000 te/d plant together with the ongoing development of the Econamine FG process. A review was carried out by Jafarinejad aimed at control and treatment of sulfur compounds, specially sulfur oxides ( $\mathrm{SOx}$ ) emissions from the petroleum industry [22]. He provided a critical and detailed introduction to the control and treatment of sulfur compounds specially sulfur oxides (SOx) emissions from the petroleum industry. He reviewed main sources and type of operations that generate SOx emissions; maximum effluent level of them from the petroleum industry; minimization, control, prevention and treatment techniques for the emissions. For calcium based sorbents, $\mathrm{SO}_{2}$ removal efficiencies between $50 \%$ and $60 \%$ were possible and for sodium based sorbents 80 percent removal efficiency was possible. Park et.al. studied absorption characteristic of continuous $\mathrm{CO}_{2}$ absorption process[23]. $\mathrm{CO}_{2}$ can be removed by various methods including absorption by chemical solvents, physical absorption, cryogenic separation, membrane separation etc. $\mathrm{CO}_{2}$ absorption by alkanol amine (MEA) aqueous solution is still considered most efficient and economical method of treatment. It was also emphasized that using high efficiency column packings in these towers could substantially improve the efficiency of the gas treating process which reduces its capital cost.

Wang et.al. discussed desulfurization and emissions control[24].They discussed dry and wet systems for $\mathrm{SO}_{2}$ removal. According to these studies, wet systems can achieve greater than 95\% SOx removal. The disadvantage is that ancillary equipment that can amount to $20 \%$ of overall plant costs. According to them, Injection of dry/semidry sorbents offers advantages of simplicity and ease of retrofit to existing plants. In this sector, according to them, there is need to carry out research on novel and efficient pollution control technologies, improved efficiency, advanced pulverized combustors, pressurized fluidized-bed combustors, and integrated gasification combined cycle systems. Basfar et.al. carried out studies on electron beam flue gas treatment (EBFGT) as a multicomponent air pollution control technology[25]. They carried out studies on the flue gas treatment for one gas each from China and Poland. EBFGT is a dry-scrubbing process of simultaneous $\mathrm{SO}_{2}$ and $\mathrm{NOx}$ removal, where no waste, except a by-product, is generated. Japan Atomic Energy Research Institute (JAERI) and Ebara Corporation laid the foundation of this technology in 80s. They concluded that development of high power electron accelerators is a crucial factor for technology implementation on industrial 
scale. Rinprasertmeechai et.al. carried out studies on use of amine-based hybrid solvent absorption system for flue gas absorption[26].They investigated the performance of hybrid solvents blended between primary, secondary, or tertiary amines and piperazine (PZ) for $\mathrm{CO}_{2}$ removal from flue gas in terms of $\mathrm{CO}_{2}$ absorption capacity and regeneration efficiency. During their investigations they found that MEA blend with $\mathrm{PZ}$ provided the maximum $\mathrm{CO}_{2}$ absorption capacity of $0.50 \mathrm{~mol} \mathrm{CO} / \mathrm{mol}$ amine while TEA provided the minimum $\mathrm{CO}_{2}$ absorption capacity of $0.30 \mathrm{~mol} \mathrm{CO} / 2 \mathrm{~mol}$ amine. Also they observed that the regeneration efficiency of TEA was 95.09 and $92.89 \%$, for the first and second generation cycles, respectively. According to Ueda et.al., the conventional method of electrostatic separation has technical difficulties when $\mathrm{SO}_{3}$ concentrations are high (60-100 ppm or higher)[27]. They developed a system called the salt solution spray system. In this system, they sprayed the upstream side of the dry ESP. This produces solid ammonium sulphate.They observed that these particles attach to electrodes and detach when they become of certain size. $\mathrm{SO}_{3}$ levels even exceeding $100 \mathrm{ppm}$ were handled by these systems. In the wet system the flue gas is cooled in cooling tower. It becomes saturated in moisture. $\mathrm{SO}_{3}$ gas changes to form a mist of concentrated sulfuric acid $(\approx 40 \%)$ with extremely fine droplets. They concluded that both dry and wet processes are not efficient at high levels. They used a two-fluid nozzle installation for salt solution spraying downward in a vertical flue. According to these studies downstream wet ESP may be considered unnecessary as salt solution spraying itself can remove $90-95 \%$ of $\mathrm{SO}_{3}$. Velan and Saravanane reviewed the studies on application of flue gas for bioenergy[28].The conversion technologies for using biomass depends on the type and quantity of biomass feedstock; the desired form of the energy; economic consideration; project specific; and the desired end form of the product. According to these studies the conversion of algal biomass into fuel can serve the purpose of flue gas treatment also. Mansourpoor and Shariati carried out studies on the biodiesel production by Two-stage transesterification of waste cooking oil[29]. They also analyzed the flue gases produced in the semi industrial boiler using this biodiesel. They observed that the trends of exhaust temperature and combustion efficiency of biodiesel were the same as petrodiesel at different air-to-fuel ratio. It was also observed by them that the $\mathrm{CO}, \mathrm{NOx}, \mathrm{SO}_{2}$ and $\mathrm{CO}_{2}$ emissions of biodiesel are lower than those of petrodiesel at different air-to-fuel ratios and two levels of energy. Jadidi and Rahmandoust carried out studies on $\mathrm{CO}_{2}$ capture [30]. They used a new blended amine (AIT 600) solution in closed loop absorption. They observed that AIT 600 solvent was an excellent solution for capturing $\mathrm{CO}_{2}$ from flue gas.

\section{CONCLUSION}

The use of proper catalyst and flue gas treatment are two important aspects for effective and environment friendly operation of petroleum and refinery units. Catalyst selectivity is most important aspect of innovations and advancements. Catalytic refining is gaining importance as it enables improvement in octane rating. Clays are used in petroleum industry for number of processes like catalytic cracking, hydrocracking, reforming, isomerization, hydrogenation, alkylation, etc. Zeolitic catalysts contribute substantially to refining and petrochemicals sector. EBFGT is a dry-scrubbing process of simultaneous $\mathrm{SO}_{2}$ and NOx removal, where no waste, except a by-product, is generated. $\mathrm{CO}_{2}$ can be removed by various methods including absorption by chemical solvents, physical absorption, cryogenic separation, membrane separation etc.

\section{REFERENCES}

[1] Sunil Jayant Kulkarni, 2015, "Process Intensification and Nanomaterials: A Short Review", International Journal of Research, 2(1), PP.392-396.

[2] Sunil Jayant Kulkarni, Ajaygiri Kamalgiri Goswami, 2014, "Research on Application of Hydrotropy: A Review", International Journal of Science, Engineering and Technology Research, 3(10), PP. 2617-2619.

[3] Sunil Jayant Kulkarni, 2015, "A Review on Research and Advancements in Extractive Distillation", International Journal of Research, 2(1), PP.306-309.

[4] Sunil Jayant Kulkarni, 2015, "Advancements, Research and Challenges in Reactive Adsorption: A Review”, International Journal of Research, 2(1), 477-480.

[5] Morris D. Argyle and Calvin H. Bartholomew, 2015, "Heterogeneous Catalyst Deactivation and Regeneration: A Review”, Catalysts, 5, PP.145-269. 
[6] Sunil Jayant Kulkarni, 2015, "Research on Biocatalysts: A Review", International Journal of Research, 2(4), PP.784-789.

[7] Sunil J. Kulkarni, 2015, "A Review on Studies and Research on Catalysts with Emphasis on Catalyst Deactivation”, International Journal of Research and Review, 2(10), PP.610-614.

[8] Sunil J. Kulkarni, Nilesh L. Shinde, 2014, “A Review On Hydrogen Sulphide Removal From Waste Gases", International Journal Of Advanced Research In Science, Engineering And Technology, 1(4), PP.187-189.

[9] Veena Ramachandran,Tanmay Uttam Gound, Sunil Kulkarni, 2014, "Biofilteration For Waste Gas Treatment- A Review", International Journal Of Ethics In Engineering \& Management Education,1(4), PP.8-13.

[10] Tanmay Uttam Gound, Veena Ramachandran, Sunil Kulkarni, 2014, "Various Methods To Reduce SO2 Emission- A Review", International Journal Of Ethics In Engineering \& Management Education, 1(1), PP.1-6.

[11] Sunil Jayant Kulkarni, Ajaygiri Kamalgiri Goswami \& Nilesh Shinde, 2015, "Treatment and Recovery for Flue Gases: a Review”, International Journal of Research, 2(6), PP.515-519.

[12] Sunil Jayant Kulkarni, Ajaygiri Kamalgiri Goswami, 2014, "Adsorption for Waste Gas Treatment: A Short Review", International Journal for Research In Applied Science \& Engineering Technology, 2(12), PP.513-514.

[13] Majid Saidi, Navid Mostoufi, Rahmat Sotudehgharebagh, 2011, "Modeling And Simulation Of Continuous Catalytic Regeneration (CCR) Process", International Journal Of Applied Engineering Research, Dindigul, 2(1), PP.115-124.

[14] Kovin A.S., Sitdikova A.V., Rakhimov M.N., 2009, "Catalytic Cracking Development And Its Role In Modern Russian Refinery", Oil And Gas Business, 1-7.

[15] C. Marcilly, 2001, "Evolution Of Refining And Petrochemicals:What Is The Place Of Zeolites", Oil \& Gas Science And Technology - Rev. IFP, 56(5), PP.499-514.

[16] Mu Xuhong, Wang Dianzhong, Wang Wengrui, Lin Min, Cheng Shibiao, Shu Zigtian, 2013, "Nanosized Moleculer Sieves As Petrolium Refining And Petrochemical Catalyst", Chinese Journal Of Catalysis, 34, PP.69-79,2013..

[17] C. Marcilly, 2003, "Present Status and Future Trends In Catalysis For Refining And Petrochemicals", Journal Of Catalysis, 216, PP.47-62.

[18] S.Reza Seif Mohaddecy, Sepehr Sadighi, Majid Bahmani, 2008, "Optimization of Catalyst Distribution in the Catalytic Naphtha Reformer of Tehran Refinery", Petroleum \& Coal, 50 (2), PP.60-68.

[19] S. W. Curry, Platinum Catalysts in Petroleum Refining, Platinum Metals Rev., 1957, 1, (2), 3843.

[20] Eman A. Emam, 2013, "Clays As Catalysts In Petroleum Refining Industry", ARPN Journal Of Science And Technology, 3(4), PP.356-375.

[21] Dan G. Chapel, Carl L. Mariz, "Recovery of $\mathrm{CO}_{2}$ from Flue Gases: Commercial Trends", the Canadian Society of Chemical Engineers Annual Meeting October 4-6, 1999, Saskatoon, Saskatchewan, Canada.

[22] Shahryar Jafarinejad, 2016, "Control and Treatment of Sulfur Compounds Specially Sulfur Oxides (SOx) Emissions from the Petroleum Industry: A Review”, Chemistry International 2(4), PP.242-253.

[23] Sung-Youl Park, Byoung-Moo Min, Jong-Sup Lee, Sung-Chan Nam,Keun-Hee Han And Ju-Soo Hyun, 2004, "Absorption Characteristic Of Continuous $\mathrm{CO}_{2}$ Absorption Process", Prepr. Pap.Am. Chem. Soc., Div. Fuel Chem. 49 (1), PP.249.

[24] Lawrence K. Wang, Clint Williford, And Wei-Yin Chen, , "Desulfurization And Emissions Control", Handbook Of Environmental Engineering, Volume 2: Advanced Air And Noise Pollution Control, 2005,2, 18, The Humana Press, Inc., Totowa, NJ,526p.

[25] Ahmed A. Basfar,Osama I. Fageeha,Noushad Kunnummal,Andrzej G. Chmielewski,Janusz Licki,Andrzej Pawelec,Zbigniew Zimek,Jerzy Warych, 2010, "A Review On Electron Beam Flue Gas Treatment (EBFGT) As A Multicomponent Air Pollution Control Technology", NUKLEONIKA,55(3), PP.271-277. 
A Review on Petroleum Refining and Petrochemical Processes with Special Emphasis on Catalysts and Flue Gas Treatment Technology

[26] Supitcha Rinprasertmeechai, Sumaeth Chavadej, Pramoch Rangsunvigit, And Santi Kulprathipanja, 2012, "Carbon Dioxide Removal From Flue Gas Using Amine-Based Hybrid Solvent Absorption", International Journal Of Chemical And Biological Engineering, 6, PP.296300 .

[27] Yasutoshi Ueda, Hiromitsu Nagayasu, Ryokichi Hamaguchi, Kazuaki Miyake, Kenji Matsuura, Chikayuki Nagata, 2012, "SO $\mathrm{SO}_{3}$ Removal System For Flue Gas In Plants Firing High-Sulfur Residual Fuels", Mitsubishi Heavy Industries Technical Review, 49(4), PP.6-12.

[28] M. Velan, R. Saravanane, 2013, "Pollution Abatement And Utilization Of Flue Gas For Bioenergy Production-A Review", International Journal Of Emerging Technology And Advanced Engineering, 3(4), PP.94-98.

[29] M. Mansourpoor, And A. Shariati, 2014, "Analysis Of Flue Gas Emissions Using A SemiIndustrial Boiler Fueled By Biodiesel Produced From Two-Stage Transesterification Of Waste Cooking Oil", Chem. Biochem. Eng. Q., 28 (1), PP. 95-103.

[30] Naghi Jadidi, Ehsan Rahmandoust, 2015, " $\mathrm{CO}_{2}$ Capturing From Industrial Flue Gases", American Journal of Oil and Chemical Technologies, 3(2), PP.34-40.

\section{AUTHOR'S BIOGRAPHY}

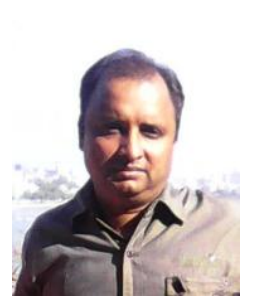

Mr. Sunil J. Kulkarni has completed his Masters in Chemical Engineering from Tatyasaheb Kore Institute of Engineering and Technology, Warananagar in 2006. He is currently pursuing his $\mathrm{phD}$ in chemical engineering. He is working as Assistant Professor in Chemical Engineering Department of Datta Meghe College of Engineering, Airoli, Navi Mumbai, India. The author has 16 years of experience in teaching and research. He has published 113 international review and research papers and presented 15 research papers in international conferences. His area of research includes adsorption, environmental engineering and catalysis. He is editorial board member of more than 25 international journals and reviewed many international papers. 